\title{
CÁRCERE FEMININO: SALA DE ENCONTROS, SUJEITOS, DE MOVIMENTOS IDENTITÁRIOS...
}

\author{
Mirna Lúcia Araújo MORAIS ${ }^{l}$ \\ José Guilherme de Oliveira CASTRO²
}

\begin{abstract}
RESUMO
Este artigo tem por objetivo desvelar os sentidos produzidos pela escrita literária expandida de Eneida de Moraes, no texto Companheiras, cujo contexto histórico - a efervescência do Estado Novo, revela pela formação discursiva utilizada pela escritora identidades ameaçadas pelas inscrições políticas culturais capturadas das experiências das presas, na cela 4, da Casa de Detenção - Pavilhão dos Primários. Lugar de retalhos de vida, de jogos de memória; tecido literário transformado em narrativa documental, visto que a seleção cuidadosa da linguagem constrói percepções das identidades feridas, já que ameaçadas por serem mulheres, bem como por serem filiadas ao Partido Comunista Brasileiro. Pelas transgressões de todas as ordens vivenciadas pela individualidade de cada uma e conferindo consciência de grupo, teremos a visibilidade de que a cela/o cárcere assume funções antitéticas: espaço das representações da tortura, de corpos seviciados, como ainda representação de intercâmbio de saberes, de um projeto compartilhado. A referência metodológica utilizada foi amparada pela revisão bibliográfica de escritos sobre identidades, constituição de 1937 e outros documentos.
\end{abstract}

Palavras-chave: Identidades feridas. Estado Novo. Narrativa Literária Documental. Cárcere Feminino. Formações Discursivas.

\begin{abstract}
The purpose of this article is to unveil the produced meanings by Eneida de Moraes 'expanded literary writing in the text Companheiras, whose historical context - the booming of the Estado Novo - reveals by the writer' $s$ discursive formation identities threatened by the cultural political inscriptions captured from the experiences of the inmates, in cell 4, of the House of Detention - Primary Pavilion. Place of life flaps, memory games; Literary fabric transformed into documentary narrative, seens how the careful selection of language builds perceptions of wounded identities, since they were threatened by being women, as well as being illicit to the Brazilian Communist Party. For the transgressions of all the orders lived by the individuality of each one and conferring group consciousness, we will have the visibility that the cell / jail assumes antithetical functions: torture's representation space, of tortured bodies, as well as representation of exchange of knowledge, ff a shared project. The methodological reference used is supported by the bibliographical revision of identity writings, constitution of 1937 and other documents.
\end{abstract}

Keywords: Injured Identities; New state; Documentary Narrative Literary; Women's Prison; Discursive Formations.

1 Doutoranda do Programa de Pós-graduação em Comunicação, Linguagens e Cultura (PPGCLC/UNAMA). Professora UNAMA/FAMAZ. Membro do Grupo Interfaces do Texto Amazônico (GITA/ UNAMA).
2 Doutor em Letras pela Pontifícia Universidade Católica do Rio Grande do Sul. É professor titular da Universidade da Amazônia (Unama), docente efetivo do Programa de Pós-Graduação em Comunicação, Linguagens e
Cultura. Líder do Grupo de Pesquisa Interfaces do Texto Amazônico - GITA/UNAMA E-mail: zevone@superig. com.br.

VOL. 14 | N. 1 | JUN. 2017 


\section{PARA INÍCIO DE CONVERSA...}

Inicio este estudo em meio a uma encruzilhada conceitual por não ter ainda clareza se a análise discursiva que colocarei em tela salta de uma narrativa literária por apresentar elementos constituintes de um texto deste gênero, a saber: enredo, conflito, personagens, espaço,... ou se, uma narrativa histórica, visto que a realidade desenhada pelo conteúdo de "Companheiras", escrito por Eneida de Moraes, nos remete a um tempo histórico marcadamente intenso pelas transformações ocorridas nas mais diferentes áreas do conhecimento.

Este artigo tem por intenção conferir sentidos a uma memória de caso ocorrida nos idos anos de 1937 - auge do Estado Novo, a partir da confecção textual da escritora paraense Eneida de Moraes, extraída da narrativa "Companheiras", momento em que fotografa como narradora e testemunha e também participante da militância de mulheres, com identidades ameaçadas pela escolha de um idealismo político contrário a ordem vigente. Fato este desvelador de desmandos sociais, ao mesmo tempo que, instrumento de resistência a luta de empoderamento feminino. De acordo com Morus (1997 apud BOGO, 2010), as identidades ameaçadas:

[...] apesar de dotado de inteligência, o ser humano tornou-se o principal problema e uma grande ameaça ao planeta. Essa ameaça põe em risco a própria existência da vida humana, como um grande homicídio coletivo. A sociedade continua fabricando os ladrões que, a seguir, enforca; disse Tomás Morus, ou educando mal as crianças que serão presas quando ficarem adultas por contestarem a ordem. (MORUS, 1997 apud BOGO, 2010, s/p)

Vale ressaltar que estaremos tratando de casos de mulheres em condição de enfrentamento, num cenário brasileiro anterior aos movimentos feministas, estes vivenciados somente nas décadas de 1960-70. A finalidade aqui se constitui no entendimento do recuo do tempo político e ação revolucionária promovida pelo gênero feminino, desencadeando questionamentos atuais advindos das outras revoluções, representações históricas nevrálgicas, colocando em evidência a fragilidade das leis protetivas, e de amparo às mulheres em situações de cárcere. Além de apontar possibilidades futuras de intervenção política para a garantia de DIREITOS; reconhecimento deste espaço feminino e dos danos sociais e culturais visíveis e invisíveis de história das mulheres do Brasil.

Conforme previsto nos artigos extraídos da Constituição de 1937:

\section{DA FAMÍLIA}

Art 124 - A família, constituida pelo casamento indissolúvel, está sob a proteção especial do Estado. Às famílias numerosas serão atribuídas compensações na proporção dos seus encargos.

Art 125 - A educação integral da prole é o primeiro dever e o direito natural dos pais. O Estado não será estranho a esse dever, colaborando, de maneira principal ou subsidiária, para facilitar a sua execução ou suprir as deficiencias e lacunas da educação particular.

Art 126 - Aos filhos naturais, facilitando-lhes o reconhecimento, a lei assegurará igualdade com os legítimos, extensivos àqueles os direitos e deveres que em relação a estes incumbem aos pais. Art 127 - A infância e a juventude devem ser objeto de cuidados e garantias especiais por parte do Estado, que tomará todas as medidas destinadas a assegurar-lhes condições fisicas e morais de vida sã e de harmonioso desenvolvimento das suas faculdades. 
O abandono moral, intelectual ou físico da infância e da juventude importará falta grave dos responsáveis por sua guarda e educação, e cria ao Estado o dever de provê-las do conforto e dos cuidados indispensáveis à preservação física e moral.

Aos pais miseráveis assiste o direito de invocar o auxílio e proteção do Estado para a subsistência e educação da sua prole.

O cenário brasileiro em pleno Estado Novo concebia a representação de Getúlio Vargas como protetor da classe trabalhadora, dada a Consolidação das Leis Trabalhistas - CLT. No entanto, esta servia para identificar as classes sociais, tendo como resultado a minoria DOMINANTE e a maioria DOMINADA.

Estas formações discursivas serviram de estratégia de enfraquecimento das categorias/cidadãos insatisfeitos - em nome de uma suposta "ordem" visando evitar nos países da América Latina, em particular, na Argentina e no Brasil, os movimentos revolucionários que estavam ocorrendo na Europa: na Alemanha (Hitler), em Portugal (Salazar) e na Itália (Mussolini)

\section{O CÁRCERE FEMININO: SALA DE ENCONTROS...}

A questão discursiva que permeará toda esta tentativa de análise da obra da escritora paraense Eneida de Moraes, enxerga na coxia das palavras escritas no decorrer da narrativa e inscritas pelos vestígios de um processo histórico de um projeto político acolhido pela gestão compartilhada entre mulheres cuja identidade ameaçada, dada a época a que estavam inseridas - os idos anos do Estado Novo - as tornavam solidárias. Daí acolherem a chegada de cada nova "companheira" fortalecendo o propósito político que as conectavam.

Importante ressaltar nesta época de revolução interna e externa que a voz do COMANDO de dentro das prisões, se espraiava por outros tantos lugares (bares, clubes e esquinas...) cuja rebeldia precisava ser resguardada como ato enunciador e, desta forma "ecoar" para além do espaço/da territorialidade nacional. Como bem documenta Eneida em seu texto: "A vida lá fora devia estar bela e com certeza ruas e avenidas ensolaradas...” (MORAES, 1989, p.133, grifo da autora).

A convicção de que existiam "companheiras" do lado de fora aspergindo notas de esclarecimento, por entre sutilezas femininas aqueciam o movimento de mudanças identitárias de um país marcado por autoritarismos, em nome de uma regulação, de uma ordem para assegurar a redefinição de uma identidade desidentificada, já que ameaçadas pela manutenção de uma lógica/ordem vigente e a possibilidade de transformação para uma outra ordem produzida pela revolução das subjetividades que as constituíam.

Com a implantação do Estado Novo, Vargas cercou-se de poderes excepcionais. As liberdades civis foram suspensas, o Parlamento dissolvido, os partidos politicos extintos. O comunismo transformou-se no inimigo público número um do regime, $e$ a repressão policial instalou-se por toda parte (PANDOLFI, 1999, p. 10).

O texto como entidade política tece as facetas do fascismo no Estado Novo, ora condição de narrador testemunha porque experimenta esta realidade e não apenas conta estórias de mulheres transgressoras, já que envolvidas em manifestos contrários a ordem vigente. Ora, descreve/fotografa/documenta as lutas internas, aqui polvilhadas de sentidos psicológicos; além das lutas externas, contexto autoritário, algoz de cada uma das 25 presas. Duplamente punidas: por subverter a cultura feminina para o lar/recatadas... - também por serem empoderadas de saber - leitura de livros e de mundo. "Datilógrafas, médicas, domésticas, advogadas, mulheres intelectuais e operárias..." (MORAES, 1989, p. 132).

Observa-se no ato de contar do narrador, a precisão com que seleciona as palavras para que o leitor seja afetado em todos os seus sentidos e apreenda/capture 
a fotografia confeccionada pela palavra. A natureza conferindo sentidos aos corpos sociais (necessidades fisiológicas, necessidades emocionais, DIGNIDADE - de que tanto proclama a atual Constituição de 1988 em contraposição a de 1937 que naturalizava e promovia a dor àqueles contrários aos interesses de Vargas. Daí a relevância do documento textual como ferramenta de denúncia e reflexão para a luta e ato de resistência:

Os dias no inverno como no verão - se arrastavam pesados, longos, sem monotonia pois nossa constante preocupação era inventar formas para que eles não fossem parecidos. Enchíamos com coragem e alegria todas as horas: ginástica, estudo, conversas, cânticos, passeio. (MORAES, 1989, p. 130, grifo da autora).

Este fragmento lembra um conceito desenvolvido por Adorno sobre reificação - momento em que os indivíduos perdem os traços de subjetividade e individualidade, passando a compor um coletivo de pessoas que tem a vida medida pela técnica. O que movia a ação destas personagens femininas era um processo de pertencimento, contrário ao que Adorno denominava: para a reificação como um processo de embrutecimento e desumanização. A monotonia era quebrada pela necessidade de se pensar VIVAS, ao mesmo tempo que tensionadas por um dano político.

Para manter aceso o propósito do partido, sabedoras das "possíveis" consequências, o cárcere tornava-se o lugar/do encontro, da afirmação dos "poderes" que embalavam a revolução a elas impostas e produzidas por elas: "Vinte e cinco mulheres, vinte e cinco camas, vinte e cinco milhões de problemas. Havia louras, negras, mulatas, morenas; cabelos escuros e claros de roupas caras e trajes modestos" (MORAES, 1989, p. 130-131).

O cárcere, então, assume uma condição identitária torna-se uma ENTIDADE, dado ao signo linguístico polissêmico que se constrói em torno dele e dentro dele, constituído de pessoas que contam estórias e fazem parte da História. Toda perspectiva de fora, a imagem do assombro, do inimigo. Na perspectiva de seus usuários - cárcere feminino - a reafirmação de identidades. $\mathrm{O}$ dano provocado àquelas mulheres pelo enclausuramento, compondo matizes, dinâmicas provocadoras de novas dinâmicas para o evento de reivindicações culturais, levando-as a se reconhecerem como grupo, característica fundamental para as relações sociais e políticas. Mas, afinal, o que tem de político na ação desta narrativa documental que reverbera para os dias de hoje desassossegos, inquietações e desconfianças textuais?

O que mudou desde o século XX - calor das inflamações do Estado Novo para o cenário constitucional deste início de século XXI - 2017, com a carta cidadã Constituição de 1988 - hoje vigente, em relação ao sistema penitenciário feminino?

Neste momento da história, evidencia-se a fragilidade da Declaração Universal dos Direitos Humanos que parece somente ser lembrada/evocada "pelos politicamente corretos" em nome de grupos específicos e de forma isolada/pontual nos "guetos identitários", mais precisamente nos meios comunicacionais, visando conferir fidelidade a dor do outro. Os discursos femininos e/ou feministas inflamados, no estilo "mexeu com uma, mexeu com todas" se esvazia dos sentidos de igualdade, fraternidade e todos os "ades" quando a situação de produção, constituinte de identidades, tem como cenário a cela - o enclausuramento.

E no adentrar no campo de identidades sobreviventes - por tratar-se de espaço de punição cujo lugar por si só desidentifica seus usuários (mulheres, mães, crianças em estágio de aleitamento), estas são desrespeitadas pela sociedade por negar, isto, NEGAR o direito de serem enxergadas/vistas como sujeitos de direito, independente dos delitos cometidos. Porque a questão não é atenuar a pena; a questão é saber que o cárcere feminino existe, que lá se encontram mulheres, mães com necessidades de ordem feminina. Indiferente a situação que enovela a narrativa e os motivos que as levaram aquele lugar, o cárcere é interpretado pelas mídias e posto em circulação social como o lugar da "punição social". 
O caos moral se dá pelo abandono, o dano identitário a elas impetrado porque como consequência deste período de "exílio" se instaura a cicatriz no campo das relações interpessoais - a desidentificação como sujeito de RESPEITO, sentimento semelhante a um ser sem nome, sem rosto. Sem falar no dano psicológico e emocional à criança em fase de aleitamento ao ser retirada antes do tempo fisiológico necessário e impor a estes indefesos à abstinência forçada, ao estado de sofrimento do nascituro.

Bernardo Sorj (2004) diz que:

[...] nos dias de hoje, a cidadania é um primeiro lugar, um mecanismo de inclusão e exclusão, delimitando quem é parte integrante de uma sociedade nacional. Sendo assim, é uma expressão de uma construção coletiva que organiza as relações entre os sujeitos sociais, que se formam no próprio processo de definição de quem, e quem não é membro pleno de uma determinada sociedade politicamente organizada. (SORJ, 2004, p. 22).

Observam-se alguns avanços da Constituição de 1937 em relação às mulheres, à Constituição de 1988. No entanto, é importante destacar que os avanços são positivados pela lei/na lei, o que não significa afirmar que estes avanços são postos em prática, como direito de todos (artigo $5^{\circ} \mathrm{CF} 88$ ), mas como direito que se autentica, pelo lugar ocupado socialmente pelos usuários desta lei.

Se por um lado observamos no Estado Novo o autoritarismo na época a que o texto de Eneida se remete e a própria personagem é afetada em sua ideologia, bem como as companheiras que comungavam do mesmo pensamento revolucionário Partido Comunista Brasileiro, o qual tem por objetivo a luta de classes e a produção de novos fluxos de ideias, capazes de proporcionar a dessacralização das ordens dominantes vindas sempre de detentores da cultura - e do saber.

Por outro lado, há quem assegure que o Estado Novo foi positivo, dada a oportunidade de produzir "mentes abertas" a respeito da cultura, da educação, a presença da escrita política literária desraizada do estilo erudito e contemplador anterior. Agora, uma escrita de reflexão de contextos até então invisíveis aos olhos dos leitores. O leitor pela literatura de Graciliano Ramos, Jorge Amado, Abguar Bastos, Ciro dos Anjos, Eneida de Moraes, acendem o fôlego do inconformismo, o anticonvencionalismo, enfim a expansão de posicionamento do contexto existente; a sociedade se desenclausura dos conceitos pré-estabelecidos.

Segundo Antônio Cândido (1990), sobre a Revolução de 1930 e a cultura:

[...] não há dúvida que depois de 1930 houve alargamento de participação dentro do âmbito existente, que por sua vez se ampliou.

[...] E também à surpreendente tomada de consciência ideológica de intelectuais e artistas, numa radicalização que antes era quase inexistente. Os anos 30 foram de engajamento politico religioso e social no campo da cultura (CANDIDO, 1990, p. 27-28).

\subsection{Potagonistas da Sala...}

Na esteira desta Revolução, a situação das mulheres seviciadas envolvidas neste processo de engajamento político busca não apenas a luta de classes, ao mesmo tempo, por sobreviver às manifestações tensionadas pelas repercussões nacionais e internacionais atreladas à estória de vida de cada uma das 25 presas políticas, na cela 4 , sem nenhuma estrutura humanamente adequada que pudesse atender às necessidades fisiológicas que à época experimentavam. Ressalta-se também a violação do 
direito de exercer a maternidade, a exemplo de:

- Olga Benário: presa em 1936, companheira de Luís Carlos Prestes, grávida de 7 meses, foi deportada no mesmo ano pela Gestapo na prisão de mulheres - Barninstrasse, onde pariu sua filha Anita Leocádia Prestes.

-Maria Morais Werneck de Castro quando se encontrava na cela $\mathrm{n}^{\circ} 4$, assistiu à chegada àquele local da alemã Olga Benário Prestes e testemunhou a companheira sentindo muitas dores e sem atendimento adequado; junto com as outras fizeram um "barulhão" para que ocorresse transferência para um hospital, o que aconteceu, mas para ser entregue a GESTAPO e mais tarde assassinada em campo de concentração.

-Eugênia Álvaro Moreyra é considerada a primeira repórter do Brasil. Em tempos de Getúlio Vargas, a polícia visitava tanto a residência que ela e o marido mantinham uma mala pronta para as situações em que fossem intimados a "dormir" fora de casa. Casa esta que reunia com frequência intelectuais e artistas como: Vinícius de Moraes, Manuel Bandeira, Tarsila do Amaral, Di Cavalcanti, dentre outros.

-Nise da Silveira: única mulher a entrar para a Faculdade de Medicina da Bahia, numa turma de 157 rapazes. Por suas atividades políticas, foi presa durante 15 meses no presídio da Frei Caneca, denunciada por uma enfermeira que mostrou à polícia política de Getúlio Vargas, os livros "proibidos" que ela guardava na sua estante.

- Beatriz Bandeira: professora, a última sobrevivente da cela 4, na casa de Detenção, no Rio de Janeiro, então Distrito Federal, também participante do Levante Comunista no Brasil. A época mãe de filhos gêmeos.

-Rosa Meirelles era:

[...] quarta filha e segunda esposa de Carlos da Costa Leite, também militou no movimento comunista, porém nunca foi oficialmente filiada ao PCB, manteve sempre uma posição independente em relação ao Partido, sendo chamada por sua postura de "prestista, mais do que comunista", em 1945 rompeu com o Partido. De forte espírito independente, segundo João Falcão: "criticava, como eu nunca ouvira antes, os defeitos e os erros do Partido e dos comunistas."80 Vivia maritalmente com Carlos da Costa Leite, porém, apesar da insistência deste, recusava-se a formalizar o casamento, que considerava uma instituição burguesa e conservadora. Teve papel ativo durante a polêmica partidária em 1945, que relataremos parte final desta dissertação, apoiando decididamente seu irmão Silo, a quem manteve-se sempre muito próxima, dando seu nome a um de seus filhos (MORAES, 1989, p. 40).

E ainda:

Bem mais explícita do que Costa Leite, no dia 11 de julho, sua esposa, Rosa Meirelles, escreve um desabafo numa folha de papel que não pretendia enviar a ninguém, mas guardou consigo. Neste desabafo Rosa Meirelles faz, entre outras, as seguintes declarações: Só um partido democrático me seduz, não aceito imposições fascistas. (...) Democracia é uma vontade coletiva - não se pode confundir com capricho de um ditador. Um tirano criminoso nunca poderá governar democraticamente, pois que na democracia não há lugar para ditador. Não nos iludamos, não pensemos que teremos possibilidades de lutar pela democracia com um governo tipicamente déspota. (...) Talvez venha a me cansar e abandonar a luta, mas por ora 
ainda me encontro como no princípio. Lamentável que se procure impor conceitos falsos a quem não os merece. Talvez ainda pior querer esconder crimes de quem ainda conserva as mãos manchadas do sangue de suas vítimas. Revolução é para mim a razão de ser da minha vida, dediquei a Ela tudo que melhor possuí, somente com Ela continuam os meus compromissos.484 Rosa Meirelles sempre foi uma ferrenha anti-getulista - muitos anos depois, numa entrevista concedida a John Foster Dulles, Rosa Meirelles declarou que a única coisa boa que Getúlio já fez foi ter se matado485 - quando Prestes inicia sua aproximação com o queremismo, ela não consegue admitir tal coisa, aliada ao fato de que Prestes endossava na direção do Partido jovens militantes muito pouco conhecidos, em detrimento dos antigos líderes comunistas, como Astrojildo Pereira e Cristiano Cordeiro e de seus antigos companheiros de tenentismo e de ANL, como seus familiares Costa Leite, Silo e Ilvo Meirelles (MORAES, 1989, p. 199-200)

-Eneida de Moraes: jornalista, mãe de dois filhos, quem a apresenta é Graciliano Ramos em "Memórias do Cárcere", ao verificar a existência da "sala 4", uma "vigorosa" conversa política ali se desenvolvia [...] dominada por um vozeirão de instrutor. Quem seria aquela mulher de fala dura e enérgica? [...] Despedi-me de Nise e desci, uma pergunta a verrumar-me, insistente, os miolos: quem seria a criatura feminina de pulmões tão rijos e garganta macha? [...] Foi Valdemar Bessa quem me satisfez a curiosidade: a mulher de voz forte era Eneida. E apertava-se uma dúzia delas na sala 4. Olga Prestes, Elisa Berger, Carmem Ghioldi, Maria Werneck, Rosa Meireles [...] (p.190, vol. 1. Memórias do cárcere. Martins: São Paulo, 6ª ed. 1969).

E, logo a seguir, ele recorda (p.191) que, na programação da "Rádio Libertadora" - que entrava no ar no mesmo horário em que o Estado Novo impunha aos ouvidos brasileiros a sua "Hora do Brasil" -, era a "voz poderosa de Eneida" que enchia o ambiente carcerário.

\subsection{Sujeições à farsa constitucional de $1937 . .$.}

Assim como estas figuras emblemáticas para o reconhecimento da ação feminina como ativistas políticas e sujeitos de direitos, deve-se também lembrar de outras tantas mulheres que lutaram incansavelmente na clandestinidade e experimentaram a fúria da nacionalização do Estado Novo e suas restrições, impondo "seus corpos" e "suas vidas", como Rosa Bittencourt - $1^{\text {a }}$ mulher ingressante no Partido Comunista no Brasil, operária desde os 7 anos de uma fábrica de linhas em Petrópolis ; também Patrícia Galvão, intelectual, escrevia numa coluna intitulada "Mulher do Povo"; Genny Gleizer, de 17 anos, judia, romena. Todas elas engajadas em movimentos femininos, na militância política.

Importante esclarecer a situação das militantes imigrantes:

Elas repercutiram no Brasil e estão até hoje presentes na discussão sobre os direitos dos imigrantes. Diante dessa conjuntura internacional entre as duas guerras mundiais, a legislação imigratória brasileira foi novamente alterada, agora pelo decreto 4247, de 1921, que regulou a entrada de estrangeiros no território nacional. A partir daí, o termo empregado passa a ser estrangeiro e a legislação posterior, além das condições exigidas para a entrada no país, trata, com minúcias, da expulsão dos indesejáveis, sobretudo aqueles que foram banidos ou 
expulsos de outro país (p.13)

E mais:

Exigia-se, claro, o visto, e além dos preceitos policiais acima arrolados, estavam especificados os velhos critérios eugenistas e morais. Os decretos do início da década de 1930 não modificaram tais dispositivos, mas incluíram ciganos, prostitutas e nômades entre os indesejáveis; e, vagamente, mencionavam “razões político-sociais" para recusar o visto de entrada. (p.14)

Todo este movimento feminino tinha como causa não apenas um partido (PCB), mas para assegurar a visibilidade feminina na sociedade civil, cujo status até então, somente dado aos homens, ou melhor, ao gênero masculino. Porque a eles caberia a decisão do que seria considerado adequado às mulheres (mães, esposas, filhas), como se pode observar no discurso de um jornal paulista em 1917, em meio a uma das greves operárias em que as atividades exercidas eram fundamentalmente resultado da ação feminina: "os agitadores tomaram conta do Brás, paralisando toda vida comercial e industrial, assaltando veículos (...) Um bando de mocinhas, infelizes operárias de fábricas, tomou conta de três bondes" (BOUNICORE e GARCIA, 2012)

A Constituição de 1937, vigente à época das personagens da narrativa "Companheiras" era uma continuidade da Constituição de 1934 definida como avançada por inovar o Constitucionalismo brasileiro já que definia no seu corpus textual o bem comum como fator preponderante. Mas, para infelicidade do povo esta Carta que traria luz para questões de ordem econômica e social, à família, à educação, à cultura, ao trabalhador, teve vida curta e pouco foi aplicada. Como elemento agravante foi seguido de uma "suposta" tentativa comunista de golpe de Estado chamada Intentona Comunista. Fato utilizado por Vargas para instaurar aprovação de Emenda Constitucional, em dezembro de 1935 declarando Estado de sítio e de guerra. Logo, neste cenário, os direitos previstos nas Constituições anteriores, a de 1937, a exemplo do sufrágio feminino (art. 108), não atinge sua efetividade:

Em 1935 houve a tentativa de um golpe de Estado pelos comunistas, chamada de "intentona comunista". O Presidente aproveitou esse momento e conseguiu a aprovação de Emenda Constitucional, em 18 de dezembro de 1935, que lhe permitia a declaração de Estado de sitio e de guerra. Em 1937 houve o golpe de Estado. Em verdade, entre 1933 e 1937, tinha-se a presença de duas ordens: uma revolucionária, conduzida por Getúlio Vargas; outra constitucional, regulada pela Constituição de 1934.

Desta forma, percebe-se que a Constituição de 1937 que deveria ser um remédio constitucional para atender as demandas do povo, surtiu um efeito contrário ao tornar-se um elemento ratificador do autoritarismo do governo. E, assim, o percurso discursivo de Eneida de Moraes, ao relatar fragmentos, histórias capturadas da realidade, retalhos de vida, imprime a substância documental da memória de uma época como matéria literária.

\section{CONSIDERAÇÕES “QUASE”FINAIS DOS MOVIMENTOS IDENTITÁ- RIOS...}

A confecção narrativa literária de "Companheiras" traz a experiência da 
contexto histórico de uma época, paradoxalmente revolucionária - o chão político social do Estado Novo - para a formação de sujeito testemunha, de autonomia, de percepção porque produtor de sentidos, ao mesmo tempo que, denuncia a situação desumana vivenciada por 25 mulheres: algumas em trânsito, outras em estado permanente num espaço revelador de identidades feridas, como também legitimadora de uma militância feminina pontuada de consciência coletiva do Partido Comunista do Brasil.

A escritora paraense fotografa com a palavra o terreno movediço de Getúlio Vargas e as ações antitéticas deste ditador. De um lado, com benefícios concretos à classe trabalhadora, à educação, à literatura; de outro, o controle e a regulação de todos esses segmentos, como instrumentos de manipulação e propagação alinhados aos interesses Varguistas para, desta forma, ter o povo nas mãos.

A cela 4 confere expressividade como espaço de troca de saberes interdisciplinares, quando proporciona ao leitor pensar a literatura "como ponte que reúne enquanto passagem que atravessa" (BHABHA, 1990). E mais, afeta as subjetividades de cada uma encarcerada pelo lugar de enunciação ocupado pela ação - ocupação - situação política por elas empreendidas. O discurso de Rosa Meirelles demonstra o nível de lucidez quanto a seus posicionamentos acerca do PCB, bem como de que o processo de consciência coletiva passa necessariamente por um tempo de inquietação.

A escritora Eneida de Moraes pelo campo da linguagem em sua narrativa proporciona ao leitor visualizar a personalidade marcante de Rosa quando ao se referir a ela no texto diz:

Os filhos de Rosa eram nossos filho. Sabiamos as graças e as manhas com quem embalavam aquela mulher forte, arrogante, atrevida sempre mas tão doce, tão enlevada pelo "menino" Quando Rosa falava nos "meninos" ficávamos todas em silêncio. Onde andariam eles? A polícia arrancara-os daquela mãe, negava-se a informar onde se encontravam, não admitia que Rosa soubesse notícia da família: o marido foragido, a irmã distante. E os “meninos"? (MORAES, 1989, p. 132)

Por intermédio do questionamento de Rosa Meirelles uma amostra da experiência de sofrimento das mães detentas por serem retiradas do convívio dos filhos e pelo desconhecimento do destino dado pelo Estado a estas crianças.Fato este ainda vivenciado hoje nas prisões femininas, no Brasil.Como c fragmento a seguir, extraído da Revista Claudia em maio de 2017,num Centro de Detenção Provisória Feminino, em São Paulo:

"Tereza, 19 anos, amamentava a filha de 2 meses quando a polícia meteu o pé em sua porta e achou 124 gramas de maconha e 60 gramas de cocaína. Na casa, em Guarulhos(SP), vivia com a sogra, que está grávida.Os homens da família não estavam . Ambas foram algemadas. "Da viatura, pedi a uma vizinha para pegar o meu bebê", diz Tereza. 'Não tenho idéia de quem esteja cuidando dela agora." (Revista Claudia-maio 2017, p. 104).

Assim como Vargas feriu ao que estava previsto no Art.127 na Constituição de 1937, que positivava:

A infância e a juventude devem ser objeto de cuidados e garantias especiais por parte do Estado, que tomará todas as medidas destinadas a assegurar-lhe condições fisicas e morais de vida sã e de harmonioso desenvolvimento de suas faculdades. 
A Constituição de 1988, cujos pilares são: Igualdade, Liberdade e Fraternidade, continua negligenciando a Resolução de 2010, quanto ao que está positivado na lei , mais especificamente nas Regras de Bangkok, quando recusa a colocar em prática a Regra 5, das Observações preliminares deste acordo com as Nações Unidas, a que o Brasil é signatário:

As Nações Unidas têm enfatizado [...] esforços para assegurar que a mulher infratora fosse tratada justa e igualmente durante prisão , processo, sentença e encarceramento , com atenção especial dedicada aos problemas especificos enfrentados pelas mulheres infratoras, tais como: a gestação e cuidados com os(as) filhos (as). (Regras de Bangkok, 2010, p.17).

Dentre os empreendimentos, a formação discursiva da autora provoca a leitura da $4^{\mathrm{a}}$ Constituição Brasileira - 1937 - e o que nela estava positivado quanto a direitos individuais e coletivos; quanto a situação dos estrangeiros no Brasil. Sem falar da importância de acordar os legisladores para as demandas dos cidadãos/cidadãs quanto a implantação da democracia e de intervenção federal, mantida inclusive na Constituição de 1988.

Ainda instituiria (a Constituição de 1937), nas legislações seguintes, novas lutas de classes pela emancipação política feminina, como bem proclamada por Luís Carlos Prestes, em 1956, na V Conferência do Partido Comunista:

[...] A própria palavra emancipação não será facilmente compreendida pela maioria das mulheres. Emancipar-se significa livrar-se da tutela de alguém, libertar-se. A luta pela emancipação da mulher compreende um trabalho imediato, mas que será contínuo e prolongado. Este trabalho representa hoje, fundamentalmente, a luta contra o atraso e a miséria. A emancipação da mulher brasileira terá início quando ela começar a compreender que é possivel ter uma vida mais justa, mais feliz e humana. Despertando para a luta, a mulher irá conquistando dia a dia a sua emancipação através da conquista de pequenas coisas: uma casa higiênica para morar, um salário digno capaz de garantir o sustento do lar, uma creche ou casa maternal para deixar seu filho bem cuidado durante as horas de trabalho fora do lar, leite, carne e pão em fartura e ao alcance de sua bolsa, etc.

Como se pode observar, o discurso de Luís Carlos Prestes é atravessado e amparado juridicamente pelas concepções e conquistas prevista na Declaração Universal dos Direitos Humanos, instituída em 1948, pós Segunda Guerra Mundial. Logo, cenário promissor para colocar em circulação social temas antes invisíveis e ou negligenciados, a exemplo do papel da mulher como ser de direitos tanto no âmbito doméstico quanto na esfera pública.

As Companheiras de Eneida de Moraes legitimam que as ações, os movimentos femininos ocorreram a duras penas - Penas aqui com uso ambíguo intencional. Dai servir de referência histórica para entender que as conquistas das mulheres não aconteceram, nem acontecerão de uma vez por todas.

Mas... enquanto existirem vozes como as de Eneida de Moraes incomodadas com a naturalidade com que a sociedade civil enxerga a barbárie vivenciada pelo outro; negando direitos fundamentais às mulheres; persistindo no descaso com as incivilidades desferidas aos seres humanos,com maior incidência sobre o gênero feminino, haverá enfrentamentos, resistências e novos mecanismos de combate às relações de poder. 


\section{REFERÊNCIAS}

As mulheres e os 90 anos do comunismo no Brasil - Primeira parte. Associação Brasileira de Anistiados Políticos - ABAP. Disponível em: http://www.anistiapolitica.org.br/abap/index.php?option=com_content\&view=article\&id=1302:as-mulheres-e-os-noventa-anos-do-comunismo-no-brasil-primeira-parte. Acesso em: $11 / 07 / 2017$.

Amor sem igual. Revista Claudia. Ed. Abril. Edição 668 - Maio de 2017, p.103-106.

BHABHA, Homi K. O local da cultura. Belo Horizonte: Ed. UFMG, 1998. 394 p. Coleção Humanitas.

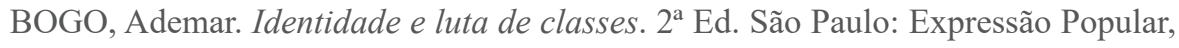
2010.

CANDIDO, Antônio. A revolução de 1930 e a cultura. In: Simpósio sobre a revolução de 1930 no Rio de Grande do Sul. ERUS, 1983.

DRAUZIO, Varella. Prisioneiras. 1 ${ }^{\text {a }}$ Ed. São Paulo: Companhia das Letras, 2017.

FERREIRA, Jorge; DELGADO, Lucilia de Almeida Neves (Org). O tempo do nacional-estatismo: do início da década de 1930 ao apogeu do Estado Novo. $7^{\mathrm{a}}$ Ed. Rio de Janeiro: Civilização Brasileira, 2015.

HALL, Stuart. A identidade cultural na Pós-Modernidade. 10 ed. Rio de Janeiro: DP \& A. 2005

LOURO, Guacira Lopes. Gênero, sexualidade e educação. Uma perspectiva pós estruturalista- Petrópolis, RJ: Vozes ,1997.

MORAES, Eneida. Aruanda. Belém, Secult: FCPTN, 1989.

PANDOLFI, Dulce (Org.). Repensando o Estado Novo. Rio de Janeiro. Ed. Fundação Getúlio Vargas, 1999. 345 p.

Regras de Bangkok - Série Tratados Internacionais de Direitos Humanos - Brasília 2016

SORJ, Bernardo. A Democracia inesperada: cidadania, direitos humanos e desiguldade social. Rio de Janeiro. Jorge Zahar, 2004.

ZIMBARG, Luis Alberto. O cidadão armado comunismo e tenentismo (1927 1945). 2001. Disponível em: file://C:/Users/Home/Downloads/zimbarg_la_me_ fran.pdf. Acesso em: 11/07/2017 